\title{
ELEGÍAS A LA MUERTE DEL PADRE EN ELOY SÁNCHEZ ROSILLO Y RAFAEL RUBIO ${ }^{1}$
}

\author{
Pedro Aldunate Flores \\ Universidad Austral de Chile. Sede Puerto Montt, Puerto Montt, Chile \\ pedroaldunate@gmail.com
}

\begin{abstract}
RESUMEN / ABSTRACT
En el presente artículo se estudian dos ejemplos de elegías en la lírica española y chilena contemporáneas: "En mitad de la noche" del poeta español Eloy Sánchez Rosillo, y "El arte de la elegía" del chileno Rafael Rubio. Mediante la visualización de escenas poéticas situadas, referidas en ambos casos a la muerte del padre, se indaga sobre la función ritual de estos textos, y se establecen diálogos y encuentros entre ambos autores, a propósito del problema antropológico y filosófico de la muerte del otro. También se sitúan estas elegías en el contexto más amplio de la tradición elegíaca de la literatura occidental.
\end{abstract}

Palabras clave: muerte, padre, elegía, Eloy Sánchez Rosillo, Rafael Rubio.

\section{ELEGIES FOR THE DEATH OF THE FATHER IN ELOY SÁNCHEZ ROSILLO Y RAFAEL RUBIO}

In this article, two examples of elegies in Spanish and Chilean poetry are studied: "En mitad de la noche" by the Spanish poet Eloy Sánchez Rosillo, and "El arte de la elegía" by the Chilean poet, Rafael Rubio. The ritual function of these texts is investigated through the visualization of situated poetic scenes which, in both cases, refer to the death of the father. Likewise, dialogues and encounters with both poets are established in relation to the anthropological and philosophical problem linked to the death of the other. These elegies are also situated in the wider context of the elegy tradition of western literature.

1 Este artículo fue escrito en el marco de la Investigación Postdoctoral: "Poesía chilena y española a partir de 1960: nombres, figuras y escenografías de la muerte", realizado en la Universidad Complutense de Madrid con el beneficio de la Beca Chile de Postdoctorado en el Extranjero, durante 2013 y 2015. 
KEYWords: death, father, elegy, Eloy Sánchez Rosillo, Rafael Rubio.

Recepción: 07/09/2017

Aprobación: 12/10/2017

Sólo quien

ve la muerte de su padre, podrá dar notable fin a una elegía.

(Rubio 2007: 34).

En el año 2008, Eloy Sánchez Rosillo², “el poeta murciano más valorado por los críticos” de España, según Ricardo Escavy Zamora (2007: 15), escribió una nota sobre la muerte de su padre que un año más tarde sería publicada en el peculiar texto: Historia del Colegio Oficial de Aparejadores y Arquitectos Técnicos de la Región de Murcia (2009). Rescato en esa nota el poema "En mitad de la noche" del libro La vida (1996), un poema que rememoraba el fatal suceso de la muerte del padre, el aparejador Isidoro Sánchez Roca, quien fuera presidente del citado Colegio desde el 9 de mayo de 1955 hasta el 4 de mayo de 1956, fecha en que Isidoro Sánchez murió, a sus tempranos 47 años, y a consecuencia de un infarto del miocardio. Eloy contaba entonces con apenas siete años y este hecho marcaría profundamente su vida y ciertamente su manera de ser poeta.

Por su parte, en el año 2007, el joven poeta chileno Rafael Rubio ${ }^{3}$ publicó uno de sus textos más celebrados por la crítica nacional: Luz rabiosa, poemario

2 Eloy Sánchez Rosillo (Murcia, 1948), poeta español, premio Adonáis de 1977 por su libro Maneras de estar solo y Premio Nacional de la Crítica en 2005 por su libro La certeza. Doctor en Filología Románica y profesor de Literatura Española en la Facultad de Letras de la Universidad de Murcia. Aunque ha sido ligado a la generación de los novísimos o generación del 70, su estética se relaciona con los llamados poetas de la experiencia, siendo evidente su filiación clásica, ajena a todo experimentalismo, donde el componente estoico y elegíaco se inserta en una cosmovisión temporalista y esencialista, en la cual la escritura sería "trasunto de lo vivencial", y donde se revela "una proximidad cómplice entre sujeto biográfico y los portavoces verbales", como señala José Luis Morante en el prólogo de la antología Hilo de oro (2014: 18-26).

Rafael Rubio (Santiago, 1975), poeta chileno, perteneciente a la generación de los 90, o "generación de los náufragos", como la llamó Javier Bello y que correspondería, según Magda Sepúlveda Eriz, a "la poesía chilena escrita durante la transición postdictatorial" (2010: 79-92). Rafael Rubio ha publicado los poemarios Arbolando (1998), Madrugador tardio (2000), 
por el cual recibiría el premio Pablo Neruda, año 2008, y que sobresale, entre otras cosas, por la "ostensible musicalidad" de sus composiciones y por el radical enfrentamiento que ahí se plantea acerca del problema de la muerte del padre; cuestión que además de situarnos en el problema de la muerte en general, nos induce a reflexionar, a propósito de sus elegías, sobre la función ritual del discurso poético, y de modo específico, sobre las problemáticas relacionadas con los procesos del duelo y del luto.

En esta línea de escritura sobre y desde la muerte, el poeta Rubio se adscribe, y de un modo en extremo transgresor, a una de las tradiciones escriturales más fértiles y profundas de la literatura occidental, la de las elegías ${ }^{4}$, cuyas fuentes se encuentran en la poesía latina (Catulo, Tibulo, Propercio, Ovidio, entre otros), en el Siglo de Oro español (Garcilaso, Góngora y Quevedo), y en las Coplas de Jorge Manrique; y que perdura en la lírica española contemporánea a través de autores como Federico García Lorca (muy especialmente en su "Llanto por Ignacio Sánchez Mejías"), Luis Cernuda (en sus libros Perfil del aire y "Égloga, elegía, oda"), Miguel Hernández, autor de varias notables elegías, y a cuya "Elegía a Ramón Sijé", Rafael Rubio alude directamente en su "El arte de la elegía"; y más tarde, en la voz del mismo Eloy Sánchez Rosillo, quien, también sumándose a esta larga tradición, publicara su

Luz rabiosa (2007), Caudal (2010), entre otros, y ha sido incluido en importantes antologías como Antología de la poesía chilena joven de Francisco Vejar (1999) y Cantares: nuevas voces de la poesía chilena de Raúl Zurita (2004). Ha recibido importantes reconocimientos por su trabajo poético, entre ellos, las becas de la Fundación Pablo Neruda (1994) y de los Talleres José Donoso de la Biblioteca Nacional (1998), además del primer lugar en el concurso "Yo no me callo" (1997), el premio de poesía joven Armando Rubio (2001) y el Premio Pablo Neruda (año 2008). Es doctor en Literatura de la Universidad Católica de Chile.

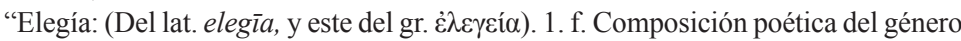
lírico, en que se lamenta la muerte de una persona o cualquier otro caso o acontecimiento digno de ser llorado, y la cual en español se escribe generalmente en tercetos o en verso libre. Entre los griegos y latinos, se componía de hexámetros y pentámetros, y admitía también asuntos placenteros" (DRAE). Por su parte, en el Diccionario de retórica, crítica y terminología literaria, se señalan las dos corrientes originales del género elegíaco: "Según el Arte poética de Horacio, que reproduce el pensamiento común de la antigüedad, la elegía procedía ya de las ceremonias fúnebres (llantos e inscripciones en honor de un difunto), ya de las acciones de gracias votivas que acompañan las obladas de los fieles. De aquí proceden los dos caracteres bien diferenciados de la elegía: la tristeza y el dolor por la muerte de alguien, la alegría que se debe al amor" (2000: 115-116). 
tercera entrega bajo el nombre de Elegías (1984) 5 . Por su parte, y ya en el contexto de la literatura hispanoamericana, se destacan las Elegías del cubano Nicolás Guillén, que sería una de las voces participantes de la "conversación familiar", sostenida a través del tiempo, por el clan de los Rubio ${ }^{6}$. Y ya un poco más cerca del territorio geográfico-poético de Chile, y en el contexto de la lírica argentina, sobresalen, muy especialmente para esta investigación, las diversas elegías de Jorge Luis Borges, situadas en diversos lugares de

5 El carácter elegíaco (o "tono elegíaco" o "actitud elegíaca") en la obra de Eloy Sánchez Rosillo ha sido estudiado por diversos críticos de su obra. Ver, en este aspecto, los trabajos de Ricardo Escavy Zamora, Antonio Roldán Pérez y Ángel L. Prieto de Paula, reunidos en el libro La poesía de Eloy Sánchez Rosillo: el ruido del tiempo (Escavy Zamora, ed.: 2007). Al respecto, señala Escavy Zamora: "La poesía de Eloy Sánchez Rosillo se mueve de la elegía a la celebración [...] El tono elegíaco con que ha sido caracterizada su obra, especialmente la anterior a la publicación de su último libro, La certeza, encuentra su manifestación más clara en su tercer libro, publicado con el título de Elegías [...] Nuestro poeta fue caracterizado como el poeta elegíaco de su generación, característica cuyas raíces se ha pretendido descubrir, agarradas en la tierra fértil de su admirado Luis Cernuda, y su querido amigo Francisco Brines [...] Pero sobre todo creo que su condición de huérfano a temprana edad tenga bastante que ver con la naturaleza elegíaca de sus poemas [...] Su libro Elegías se sitúa "en el centro de su andadura estética" sintetizada por la oposición entre dos fuerzas, la de la belleza de lo recordado, y la de la melancolía de la evidencia del presente" (2007: 15-28). Por su parte, y respecto del poemario Elegías, señala José Luis Morante: “el poeta recupera un título tradicional, utilizado por nombres preclaros como Garcilaso, Bécquer, Juan Ramón Jiménez o Luis Cernuda, aunque podemos retroceder en el legado lírico hasta la elegía grecolatina, cuando la forma expresiva tenía un carácter formal más que temático" (Cit. en Sánchez Rosillo 2014: 48).

6 Ver, en este aspecto, el interesante prólogo del mismo Rafael Rubio a la obra $\mathrm{Ni}$ tallo ni renuevo, publicada en 2015, y la cual recopila algunos de los mejores textos de los tres poetas emparentados: Alberto Rubio (abuelo), Armando Rubio (padre) y Rafael Rubio (hijo). El poeta invita a leer el texto no tanto como una antología, sino más bien como una conversación familiar: "Me gustaría que este libro fuese leído como una conversación familiar; sostenida entre abuelo, padre e hijo, pero también entre ellos y otros familiares recónditos, algunos ya mencionados en este prólogo: Vallejo, Quevedo, Góngora, Machado, Mistral, Pezoa Véliz, Nicolás Guillén, Lorca, y tantos otros, con quienes los Rubio han mantenido cordialidad fraterna" (2015: 19). A partir de esta sugerencia de lectura, me gustaría enmarcar este artículo en el contexto de un diálogo fraternal entre los poetas (y entre sus fuentes), o si se puede, más que un ejercicio de lectura intertextual o comparada, como una manera de adentrarse en la "biografía de un diálogo", aun cuando en el caso específico de la relación entre Sánchez Rosillo y Rafael Rubio, este posible diálogo o encuentro, sea más bien hipotético y/o imaginario. 
su Obra poética ${ }^{7}$, y cuyo autor sería un referente indiscutible para el poeta Rafael Rubio, tal como él lo ha manifestado en diversas reflexiones sobre su poesía, siempre en constante diálogo con la tradición que lo ha precedido, y de manera especial, con la propia tradición lírica familiar, de la cual él sería su más joven y vivo representante.

Un año más tarde de la publicación de Luz rabiosa, en abril de 2008, el poeta Rafael Rubio era entrevistado por Cristián Warnken en su programa Una belleza nueva. De aquella entrevista, motivada por la entonces reciente publicación de Luz rabiosa, me interesa destacar, en primer lugar, lo que va comentando Warnken a propósito de la filiación de Rubio con los poetas de Siglo de Oro español, ya que el autor los reconoce como influencia directa de la poesía de su abuelo, el poeta Alberto Rubio. En segundo lugar, me interesa rescatar lo dicho en esa ocasión sobre la muerte del padre de Rafael, el también poeta Armando Rubio, fallecido a sus 25 años en dudosas y trágicas circunstancias, un 6 de diciembre de 1980. El terrible hecho habría que recordar aquí que Armando Rubio murió cayendo del sexto piso de un edificio de la calle Coronel Bueras $\mathrm{N}^{\circ} 146$, en Santiago- marcaría profundamente la vida de Rafael, quien contaba entonces con tan solo 5 años, y ciertamente determinaría el carácter trágico y elegíaco de su posterior poesía. En la entrevista, el poeta Rubio se refiere con estas palabras a la historia -o intrahistoria- de Luz rabiosa:

7 Quisiera dejar en suspenso aquí, la relación entre las elegías dedicadas al padre, en Sánchez Rosillo y Rafael Rubio, respectivamente, y una de las elegías de Jorge Luis Borges, que también trata sobre la muerte del padre: me refiero al poema "A mi padre", del libro La moneda de hierro de 1976. También me gustaría abrir la relación con ese otro texto, llamado precisamente "Elegía", del libro La rosa profunda de 1975, que introduce, hacia el final, un giro hacia la propia-muerte, de modo que la elegía deviene autoelegía, tal como ya se había sugerido en aquella otra "Elegía", del libro El otro, el mismo, de 1964. Asimismo, también resulta interesante, para nuestra lectura, aquella "Elegía" del libro La cifra, especialmente porque en ella el tiempo pretérito es, con sus símbolos y arquetipos, el motivo de la elegía. Otras elegías de Borges, que bien pueden ser de interés para futuras investigaciones sobre el tema, son: "Elegía del recuerdo imposible" y "Elegía de la patria", también del libro La moneda de hierro; y los textos "Elegía" y "Elegía de un parque" del libro Los conjurados de 1985; pero también muchos otros poemas de Borges, no titulados directamente como elegías, se pueden leer en clave elegíaca, como por ejemplo, el poema "Cristo en la cruz", también del poemario Los conjurados, y que es el primer texto del que fuera el último libro de poemas publicado por el autor argentino. 
Luz rabiosa nace fundamentalmente de una experiencia traumática e inexplicable como es la muerte del padre. Todos los poemas nacen a partir de esa experiencia. Por lo tanto el tratamiento que hago de la muerte en este poema, en este libro, no es un tratamiento a la muerte en términos abstractos -una reflexión acerca del sentido de la muerte- sino más bien se trata de afrontar y de dar cuenta de una muerte concreta, particular, absolutamente cercana. No hay una reflexión metafísica acerca de la muerte. Y estos poemas entonces surgieron como una manera de domar el dolor, de domesticar el dolor (Cit. en Warnken 2008: 8).

Dos son, entonces, los propósitos de este artículo. Primero: situar y describir las escenas elegíacas proyectadas en los textos "En mitad de la noche" de Eloy Sánchez y "El arte de la elegía” de Rafael Rubio. Y segundo: establecer ciertos diálogos, encuentros y/o correspondencias en torno al sentido de estas elegías, indagando sobre la posible función ritual de los dos textos, muy especialmente en lo que respecta a los procesos del duelo y del luto, y en cómo la escritura poética podría ser una forma de expresión y asimilación de dichos procesos. Para efectos de análisis se visualizan estos textos como escenas poéticas situadas ejemplarmente en la muerte, colgándose del concepto de "poesía situada", acuñada por Enrique Lihn y llevada al extremo en la escritura de su libro Diario de muerte. En esta línea de lectura o de interpretación, las escenas relativas al morir y a la muerte serían, de acuerdo con Lihn, las escenas situadas por excelencia, con la salvedad, para los casos de Sánchez Rosillo y Rubio, de que el problema en cuestión sería aquí el conflicto de la muerte del otro, el cual conduciría, en última instancia, al asunto de la muerte propia.

\section{A PARTIR DE “EN MITAD DE LA NOCHE” DE ELOY SÁNCHEZ ROSILLO}

El estudio sobre la elegía en la obra del poeta murciano ha sido profundizado de modo exhaustivo por el crítico Ángel L. Prieto de Paula, en su artículo "La elegía y la construcción del presente en Eloy Sánchez Rosillo", quien logra precisar la relación entre el carácter elegíaco en Sánchez Rosillo y el marcado acento autobiográfico de su obra. Dos causas determinan, para Prieto de Paula, el desarrollo de su producción poética: 
La naturaleza argumental de esta obra, netamente elegíaca, y su confesionalismo [...] o, si se quiere, la vinculación entre asunto poético y la vida del autor, que los propios versos evidencian [...]. Por tanto, la evocación elegíaca en el caso de la poesía de Rosillo no puede enriquecerse multiplicadamente con materia ajena, cultural o de carácter reflexivo general, por más que de todo ello haya en esta poesía; sino que depende estrechamente del acervo experiencial, humilde y limitado, de un hombre sólo (y, ahora sin tilde, solo). (Cit. en Escavy 2007: 100-101).

Empero, para Prieto de Paula, es en el libro Autorretratos (1989), y no en Elegías, donde el poeta alcanza "la máxima densidad de lo elegíaco": "La muerte está aludida en toda su obra, pero nunca se había producido una presencia tan inquietante como la que se instala en este libro -léase el poema «La intrusa» ${ }^{8}$, del mismo título y tema que otro de Unamuno de Rosario de sonetos líricos"- (Cit. en Escavy 2007: 110). Por nuestra parte, creemos que esta situación responde a un pulso interno, que obedece a la asimilación constante y sostenida, a través del tiempo y la vida, de los procesos del duelo y del luto. En efecto, de la muerte del padre, en el libro Elegías, poco o casi nada se dice, o bien, lo que está dicho al respecto, se dice a través del silencio. Es a partir de Autorretratos que las figuraciones de la muerte empiezan a hacerse más visibles en la obra del poeta, de manera especial en el texto citado por Prieto de Paula, hasta llegar a una alusión directa al hecho biográfico de la muerte del padre, en el texto "En mitad de la noche" del poemario $L a$ vida, que ha sido fechado de modo preciso por el autor el día 4 de julio de $1995^{\circ}$, es decir, casi cuarenta años después de la muerte del padre del poeta.

8 Desde el punto de vista del estudio de los nombres y figuraciones de la muerte, este poema resulta significativo: la muerte es "La intrusa", figura femenina, nocturna y acechante; dueña y señora, presente y ausente a la vez, cercana y lejana, triunfante sobre el mundo de la naturaleza y la vida; pero que, sin embargo, canta "una canción dulcísima", mientras sus labios entretejen el nombre del poeta con su música (Sánchez Rosillo, 2014: 221-222). El poema cierra el libro Autorretratos del año 1989 y es importante para comprender, desde el propio discurso poético, la relación que el poeta va estableciendo con la muerte a través de su obra.

$9 \quad$ Eloy Sánchez Rosillo siempre incluye una cronología con la fecha definitiva de la redacción final de cada uno de sus poemas, lo que aproxima esta poesía al género autobiográfico, a los diarios de vida y las memorias. En la entrevista de Ana Eire, el poeta explica esta elección: "La tabla cronológica es una forma cómoda de tener en limpio y siempre a mano el itinerario temporal de los poemas. Otra explicación que puede tener esta costumbre mía de incluir al final 
Ahora bien, me parece oportuno precisar, al respecto, que este movimiento entre lo no dicho y lo dicho sobre la muerte del padre, o entre el silencio y la palabra que evoca esa muerte, se inserta dentro de un proyecto general de poesía elegíaca, que eleva esta forma poética a lo que podríamos llamar una metapoesía elegíaca, es decir, una poesía concebida, en tanto arte poética, propiamente como elegía. Esto, evidentemente, se relaciona con el marcado carácter autobiográfico de la poesía de Eloy y con su manera de pensar el tiempo, la vida y la muerte. Al respecto, es el propio autor quien, en entrevista con Ana Eire, explica la condición elegíaca de su obra, pero haciendo alusión a las dos acepciones originales de esta forma de escritura:

Sí, mi poesía, desde siempre, desde el principio, es una poesía elegíaca, en el sentido en el que yo la entiendo. La poesía elegíaca es en el fondo igual que la poesía celebrativa -la poesía en realidad siempre celebra-, lo que ocurre es que aquello a lo que te refieres cuando escribes un poema elegíaco, aquello que celebras, es algo que ya está en el pasado, algo que fue presente y que el tiempo te quitó de las manos (Cit. en Eire 2005: 137).

¿Qué fue, en suma, aquello arrebatado por el tiempo, aquello que el tiempo -y por lo tanto la muerte- le quitó de las manos al poeta? Sin más y quizás en primer lugar: el padre. De ahí surge este "tono" o "actitud" elegíaca que impregna, de modo profundo, y de parte a parte, la obra de Eloy Sánchez Rosillo. Pero para hablar de esta muerte hubo que callar mucho tiempo -casi cuarenta años hemos dicho-, tiempo durante el cual se perfeccionó el arte de la elegía en este autor, es decir, la forma elegíaca elevada a arte poética, tal como más tarde y ya en territorio chileno, lo haría el mismo Rafael Rubio. Pero, ¿por qué callar tanto tiempo dicha muerte? ¿Por qué no escribir antes la elegía al padre muerto? ¿Se trata realmente de algo no dicho, de algo silenciado?

Creemos, en esta línea de lectura, que lo no dicho sobre la muerte del padre se dice sobre el tiempo. Si la muerte es aquella figura que se presiente, aquella "Intrusa" que se está esperando, para emprender "juntos / el más largo

de cada libro la cronología de las distintas composiciones está en el carácter autobiográfico que tiene mi poesía. Como los poemas no están ordenados en los libros cronológicamente, la cronología puede ayudarme a mí y podría ayudar a alguien que se interesara por mi poesía a ordenar esta especie de autobiografía que hay en mi obra" (2005: 50). 
viaje" (del poema "La intrusa"), y que el poeta advierte como una presencia acechante, de alguna forma, y por medio de la palabra poética, aquella presencia se está conjurando, en la medida en que está siendo figurada, y con ello el poeta va estableciendo, a través del tiempo y mediante la escritura, un espacio "de soberanía" con la muerte, o lo que es lo mismo, una "relación de poder", y acaso una "relación de libertad" ante la "alta potencia de la muerte", como lo explica Maurice Blanchot a propósito de Kafka ${ }^{10}$.

Señala el sujeto del poema "Este abril" del libro Autorretratos: "De pronto, siento / una proximidad que me estremece, / una presencia, una inquietud, un frío, / la certeza de no encontrarme solo / en esta habitación. Alzo, asustado, / la pluma del papel. Y está la muerte / mirándome a los ojos" (2014: 208). Es posible, entonces, enfrentar a la muerte, mirarla a los ojos, en tanto ésta se va convirtiendo en figura en el poema. La muerte del padre, en cambio, aquella muerte que al propio Eloy le arrebató su infancia, es de algún modo casi indecible, impronunciable. Y entonces la muerte, que paradójicamente es el efecto del paso inexorable del tiempo, se oculta en el mismo tiempo y es, en definitiva, aquello que no se puede contar, aquello que se esconde en los pliegues infinitesimales de la memoria. Si no se puede hablar del padre muerto, entonces se hablará del tiempo: aquel que ya pasó y de todo lo que irremediablemente ya fue, tal como se desprende del poemario llamado Elegías. De este modo, todo deviene elegía y el tiempo, al final, sería el personaje principal de esta elegía continuada. Todo el devenir, todo lo vivido y lo contado, "las cosas como fueron", serán el tema de esta poesía, y detrás de este asunto poético, se hablará, casi sin palabras, del padre muerto (pero también de la madre muerta, como veremos más adelante).

En esto consiste la resistencia elegíaca de Sánchez Rosillo y el consiguiente modo de transfigurar el dolor en celebración. En este sentido, se cumplen, siguiendo al propio autor, las dos líneas argumentales de la elegía: "Es decir,

10 Remito aquí a diversos pasajes de los ensayos de Maurice Blanchot sobre Franz Kafka, especialmente en sus libros El espacio literario (2000) y De Kafka a Kafka (2006). En palabras de Blanchot: "Kafka siente profundamente que el arte es relación con la muerte. Quien dispone de ella, dispone extremadamente de sí, está ligado a todo lo que puede, es íntegramente poder. El arte es dominio del momento supremo, supremo dominio" (2000: 82-83). En otro lugar, el autor señala: "Unos y otros (escritores) quieren que la muerte sea posible, éste para aprehenderla, aquéllos para mantenerla a distancia. Las diferencias son insignificantes, se inscriben en un mismo horizonte que consiste en establecer con la muerte una relación de libertad" (2006: 181). 
lo que hago yo en mis poemas, por lo general, es una especie de celebración póstuma de momentos hermosos, una celebración póstuma de la alegría"; y luego: "Yo, además, por lo visto, tengo un temperamento elegíaco extremo, que me lleva incluso a ver y sentir el presente como pasado". Pero insiste el poeta: "Yo no veo grandes diferencias entre la celebración y la elegía. Es lo mismo visto desde distintos momentos del tiempo, desde distintas perspectivas" (Cit. en Eire 2005: 137-138).

Lo anterior nos conduce a una consideración sobre la naturaleza de la misma muerte, en la cual metafóricamente se condensan todos los tiempos: todos los pasados vividos, incluso el presente, y más aún, todos los futuros posibles. Es así que, como señala el poeta, "lo que vivimos sólo está completo cuando está en el pasado, y es entonces cuando adquiere o no definitivamente su relevancia" (Cit. en Eire 2005: 139). En suma, la muerte le otorga sentido a la vida, en el sentido de que la completa, la termina, la convierte en unidad, pues el ciclo vital se ha cerrado y solo entonces es posible mirar esa vida en retrospectiva, pero no ya desde la desesperanza o la honda tristeza -"sentimientos estériles" para Eloy Sánchez Rosillo- sino, muy especialmente, desde la melancolía que muy pronto da paso a la celebración. De esta forma, la evocación ya no es dolorosa o, dicho de otro modo, el dolor se doma o domestica mediante la escritura, tal como también lo entiende Rubio.

Volvamos, en este aspecto, al citado poema sobre la muerte del padre de Eloy, el aparejador Isidoro Sánchez Roca, a partir del cual se comprenderá, con mayor claridad, la función ritual de esta poesía elegíaca o, dicho de otra manera, la intención de dar luz sobre el trágico acontecimiento de la muerte, ese "hecho de la empiria que tiene lugar en ocasiones ante nuestros ojos" y que, sin embargo, sigue siendo "un misterio de dimensiones metaempíricas, es decir, infinitas, o mejor aún sin dimensiones de ninguna clase" (Jankélévitch 2009: 18).

Además del evidente rasgo autobiográfico y narrativo del poema, y de su tono evocador y nostálgico, me interesa destacar la oposición simbólica de los elementos luz y oscuridad que constituyen, según mi parecer, la base mitopoética de la poesía elegíaca de Eloy Sánchez Rosillo, desde la cual surge su intención ritual, es decir, la necesidad de experimentar el duelo y el luto y, por consiguiente, de experimentar una forma de salud, sanación o purificación. Para ello, sin embargo, debe haber una agonía y un conflicto, e incluso quizás una catarsis que, en este poema, se resuelve aparentemente mediante la distancia evocadora y retrospectiva que el sujeto establece respecto del relato autobiográfico. El relato se vuelve escena en el poema, a través 
de la evocación que resulta de la mirada del autor. Hay, de este modo, dos luces que se encuentran en pugna en el poema-escena: la luz oscura de la muerte y de la noche; y la luz radiante de la aurora, que apenas se atisba en el poema, cuando ya la muerte ha sido consumada... "en mitad de la noche".

Dice el yo poético: "En mitad de la noche me desperté. Y había / mucha luz en la casa". Con estas palabras, el poeta nos introduce en la escena situada de la muerte del padre: "Sin duda, / algo extraño sucedía. Asustado, confuso, / llamé con insistencia a mi madre, mas nadie / acudió de momento. Porfié, y al fin vino / a mi cuarto, afligida, la sirvienta, y después / de acariciarme un poco y abrazarme, la pobre, / me dijo como pudo que mi padre había muerto, / que había muerto hacía un rato, de repente" (Sánchez Rosillo 2014: 238). La escena nos transporta al pasado, pero de inmediato el sujeto -que es aquí una figuración del poeta, puesto que el poema es "indisimuladamente autobiográfico"- nos sitúa en el presente de la escritura: "Casi cuarenta años han pasado y aún / respiro aquella angustia. Mientras mi mano intenta / escribir estos versos, voy viviendo de nuevo / los momentos terribles de aquella noche remota". ¿Pero qué le conmueve al pequeño Eloy?: no la muerte ni el cadáver "-tan irreal, tan solo en su quietud-", sino el llanto de la madre, que yace junto al cuerpo del padre muerto: "Mi madre está sentada en un sillón, llorando / con tal desconsuelo junto al lecho en que yace / el cuerpo de mi padre. Yo me acerco y la beso; / le digo que no llore, que no llore" (238). Es de súbito que la muerte, esa evidencia de hecho que sucede brutalmente ante nuestra mirada, nos revela su nada y su vacío, y entonces el enigma se despliega en todas sus dimensiones metaempíricas.

El muerto no sufre, no llora ni se mueve, nada. Nada hay, en definitiva, en el muerto; pues cuando la muerte es, los muertos nada son, como lo enseñara Epicuro. Pero los que sobreviven a la muerte deben experimentar el duelo y el luto, que parecen no terminar; deben ver la muerte y ésta, de suyo, trasfigura: "La muerte transfigura, traza súbitamente / un enigma en su presa, y no reconocía / apenas a mi padre en aquellos despojos / misteriosos, herméticos". Se entiende, de esta manera, que el sujeto del duelo no es el muerto, sino el doliente, quien viendo morir al ser querido, experimenta figuradamente su propia muerte, pero sobreviviendo a la muerte del otro. Dice el sujeto: "Entonces no lo supe. / Pero hoy sé que esas horas en que tomé conciencia / del tiempo y de la muerte arrasaron mi infancia / Dejé allí de ser niño".

Finaliza el poema-escena con la ausencia de la luz, con la noche interminable de la muerte, detrás de la cual apenas se atisba la luz de la aurora, que es 
símbolo aquí de luz maternal y por lo tanto de vida. Dice el poeta: "La casa fue llenándose / poco a poco de gente. Familiares y amigos / daban con su presencia lugar a repetidas / escenas de dolor. La noche no avanzaba. / Parecía que nunca iba a llegar la aurora" (239). Sin embargo, la presencia más doliente es aquí la de la madre, en cuyo dolor se enfoca la mirada y se sensibiliza el oído del pequeño Eloy. Es el llanto de la madre el que punza y hiere -para el niño Eloy y para el poeta Eloy ya adulto- pues en la figura de la madre se concentra toda la tragedia del devenir mortal de la existencia. Es ella quien debe soportar la muerte con sus lágrimas y frente a ello, el personaje Eloy -hombre devenido niño y niño devenido hombre en el poema- será tan solo un espectador más del acontecimiento ${ }^{11}$.

En definitiva, como señala Ricardo Escavy Zamora a propósito de lo elegíaco en Sánchez Rosillo: "La poesía elegíaca canta el gozo que ha quedado atrás con el paso inexorable del tiempo, que, con la pátina con que la distancia lo baña, hace que el canto se tinte a su vez de melancolía y adquiera la calidad de un «cierto lamento»" (2007: 16). Pero ese lamento, hemos visto, nace de circunstancias autobiográficas precisas y dolorosas: la muerte del padre, en mitad de la infancia del poeta; y más tarde, pero de un modo más sosegado, pero igualmente punzante por lo enigmático y súbito de la muerte, la muerte de la madre. A partir de aquellas muertes todo se impregnará de elegía: la cosmovisión del tiempo y de la vida, hasta la propia figuración del poeta en su obra.

$\mathrm{Al}$ respecto, diversos poemas del autor testimonian bellamente el paso desde la visión de la muerte del otro (aún no aludida explícitamente en el

11 En el año 2008, Eloy Sánchez Rosillo publica el poemario Oír la luz. El segundo poema del libro lleva por título "Madre". El texto establece un diálogo implícito con el poema "En mitad de la noche", en tanto se alude, nuevamente, al arrebato de la niñez provocado por el acontecimiento de la muerte. También, en ambos poemas, se refiere a la muerte como misterio o enigma y como hecho súbito que arrasa con la vida; pero esta vez la mirada elegíaca se proyecta desde la ternura que caracteriza el sentimiento filial entre madre e hijo. Cito el poema: "Llegué cuando acababa de morir, / y era un misterio ver tan de cerca la muerte / en aquel cuerpo amado. / Aún conservaba el calor de la vida, y puse yo mis labios / sobre su rostro inmóvil. Al besarla, pude atisbar en ella y escuchar todavía / unas puertas cerrándose, / y un viento que de súbito arrasaba / la casa del amor y no sé qué despojos / de mi niñez remota" (2014: 287). Según José Luis Morante, en el poema se "entremezclan el dolor sosegado con la distancia requerida para superar la angustia, tormentosa y oscura. La definitiva separación permite el desconsuelo del recordar y halla en la memoria un seguro refugio" (Cit. en Sánchez Rosillo 2014: 66-67). 
momento de la publicación del poemario) a la muerte propia. Basta leer el poema "Epitafio", con el cual se cierra el libro Elegías, para ejemplificar lo anteriormente dicho, y para dar cuenta, de modo específico aquí, del paso desde la forma elegíaca al epitafio propiamente tal, en donde el poeta se sitúa finalmente en su propia muerte y fuera del tiempo, pero apelando al rasgo celebrativo que el propio Eloy Sánchez Rosillo identifica como elemento central de toda elegía:

Detened, caminantes, vuestros pasos.

Sabed que aquí reposa alguien que amara mucho.

La hermosura del mundo: los árboles, los libros,

La música, el verano, las muchachas.

No preguntéis quién fue, ni desde cuándo

Es ya silencio, olvido de las cosas.

En la tierra que cubre sus despojos,

Plácidamente descansad un rato.

Y proseguid después vuestro camino

Bajo el propicio sol que en su noche os desea (2014: 187).

\section{“EL ARTE DE LA ELEGÍA” DE RAFAEL RUBIO}

Para entrar en la lectura del poema "El arte de la elegía" de Rafael Rubio, quisiera retomar aquí algunas consideraciones de Ricardo Escavy Zamora sobre la elegía. Señala el crítico español:

Dentro de la preceptiva, la elegía, más que quedar definida tanto por el contenido como por la forma, resulta indefinida. Por lo que respecta a la forma, en nuestra lengua debería estar escrita en tercetos o verso libre, en griegos y latinos en hexámetros o pentámetros. Por lo que al contenido se refiere debe corresponderse con un lamento por la muerte de un ser próximo, normalmente querido, o como consecuencia de cualquier otro acontecimiento digno de ser llorado (2007: 26).

Pues bien, y a propósito de lo dicho en clave metapoética sobre la elegía en el poema de Rubio, pensamos que en este caso el sujeto del texto define de modo explícito, y tanto en forma como en contenido, el significado de lo que para él sería una buena elegía, y con ello el poeta chileno se sitúa con decisión y con una sorprendente lucidez frente a la tradición elegíaca que, recordemos, se traspasa a su obra a través de las lecturas compartidas con su 
abuelo, el poeta Alberto Rubio, del Siglo de Oro español y de ciertos textos específicos que el autor reconoce como antecedentes directos de su elegía ${ }^{12}$.

Es así que en el poema se señalan, de modo explícito, ciertos procedimientos formales -retóricos y poéticos-, que definirían, según Rubio, el arte de la elegía. En este sentido, y conforme al carácter metapoético del texto, el poema se definiría a sí mismo, presentándose al lector sobre todo como construcción verbal o artificio del lenguaje; mientras que el trabajo de la escritura sería, para el poeta, un ejercicio, tarea u oficio emparentado estrechamente aquí con la tarea de comprender la muerte del otro y por extensión, la propia muerte.

12 El 28 de enero de 2015, tuve la oportunidad de entrevistar personalmente a Rafael Rubio. En dicha entrevista el poeta me contó algunos detalles de la construcción del poema "El arte de la elegía". El autor sitúa diversos textos como antecedentes indirectos y directos de su elegía. En primer lugar, destacan los poetas del Siglo de Oro español, a los que cita explícitamente en su texto: Quevedo, Fray Luis y Góngora, además de Garcilaso y las Coplas de Jorge Manrique. Además, el autor nombra otros textos específicos como el "Planto por la muerte de Trotaconventos" de Juan Ruiz, Arcipreste de Hita; el "Llanto por Ignacio Sánchez Mejía" de Federico García Lorca; la "Elegía a Ramón Sijé” de Miguel Hernández; y el "Réquiem" de Humberto Díaz Casanueva. Por otra parte, el autor señala como influencia directa la poesía de Enrique Lihn, en especial su Diario de muerte y reconoce la importancia de la noción lihneana del sujeto como máscara, personaje o simulador, todo ello en concordancia con la noción de la "poesía situada" especialmente en la muerte y en la concepción del texto como construcción metapoética e intertextual. Asimismo, la crítica ha reconocido la influencia de Nicanor Parra en la obra de Rubio, evidenciándose que la creación poética es inminentemente una construcción en el plano del lenguaje, diferenciándose de este modo de la poética confesional y/o autobiográfica de Eloy Sánchez Rosillo. A propósito de la influencia de Parra en la obra de Rubio, señala Magdalena Infante: "Rubio se expresa en un tono antipoético que, recordando la ironía de Parra, acepta toda la realidad de la construcción del poema y pone de manifiesto - como señala Pessoa- que ha fingido que es dolor el dolor que en verdad siente. Porque, para Rubio, el trabajo del escritor no es diferente al del albañil. Este poeta considera la poesía como un oficio más, un trabajo de manufactura en el que la única diferencia con el artesano está en que la materia sobre la que se trabaja es el lenguaje" (2008: 227). Me parece oportuno contrastar lo anterior con las palabras de Eloy Sánchez Rosillo, en la entrevista realizada por Ana Eire: "Yo nunca hablo de construcción ni de invención, sino de creación. Hay gente que dice que construye el poema, que inventa el poema, que el poema funciona de esta forma o de la otra. Los aparatos son los que se inventan y funcionan, y no los seres vivos; los seres vivos respiran, laten. El poeta no es un inventor. Yo tengo la convicción de que el poema se hace de una manera muy misteriosa, por lo menos a mí me sucede así. Se va haciendo solo. Yo, como antes te he dicho, colaboro lo que puedo, desde luego, a que eso sea. Y por otro lado, claro, la poesía tiene una parte indiscutible de oficio. Conocer lo mejor posible el oficio es obligación del poeta. Sin el oficio no se puede hacer nada, pero ese conocimiento técnico es algo que hay que dar por supuesto en el poeta, como el valor en el soldado" (Cit. en Eire 2005: 145-146). 
Para alcanzar esa comprensión de la expiración del otro, el poema presentará una escena: la escena propiamente tal de la escritura elegíaca, en la que se enuncia, como veremos, una intención ritual. Es así que el sujeto demanda un espacio y una acción, donde a su vez se llama a la realización de un rito o, mejor dicho, a la conclusión o cierre del mismo: "El oficio / se ejerce en la oscuridad o en el abismo / o en una mesa de disección. / No habrá de ser / de otra manera la escritura, si se quiere / ver la muerte morir en el poema" (Rubio 2010: 32).

"El arte de la elegía" ocupa un lugar central en el libro Luz rabiosa y bien se puede leer como arte poética, es decir, como metapoema que describe y explica las claves de la construcción del discurso poético del autor. De este modo, el poema simula y sugiere una metaescena, donde a su vez el sujeto se simula a sí mismo como el escribiente de la elegía, es decir, como el propio poeta Rafael Rubio ${ }^{13}$. Con ello, el poema adquiere un tono didáctico, que se logra aquí por medio del efecto de distanciación o extrañamiento del sujeto y por la emergencia de una conciencia metapoética que logra neutralizar la emoción mediante la ironía. El arte de la elegía es una simulación, un rito para llegar "al justo término", para "dejar que se complete la muerte" (29). La muerte, de esta manera, "está viva en el poema", y es necesario trabajar con ella para dar "notable fin a la elegía", es decir, para rematar la muerte del padre o terminar de una buena vez con ella, y así "ver la muerte morir en el poema". Rafael Rubio es ante todo un poeta de oficio: concibe el poema, de modo explícito, como construcción del lenguaje -“el poema, un edificio cuyo lujo te avergüenza" (32)-, pero también como espacio ritual, donde literalmente se demanda un cuerpo, porque no hay ritual sin la demanda de

13 En la poesía de Rafael Rubio habría un fuerte "sustrato o un estímulo autobiográfico", que lo podría aproximar, en cierto sentido, a la obra del murciano Sánchez Rosillo, cuya inspiración poética surge de un marcado anclaje autobiográfico. En Rubio, sin embargo, el traspaso de la vida a la obra se lleva a cabo de otra manera, pues él concibe el poema, y la construcción del sujeto poético, como un artificio en el plano exclusivo del lenguaje o de la ficción poética propiamente tal. Lo anterior lo aproxima más a la antipoesía de Parra, a la escritura de Lihn, y a la literatura de Borges. Para contrastar con lo dicho por Sánchez Rosillo, cito al propio Rubio: "La mayor parte de lo que escribo tiene un sustrato o un estímulo autobiográfico, que deformo deliberadamente hasta lo grotesco, con el propósito de difuminar lo más posible esa referencia, sin destruirla por completo. Que el poema sea su propia autobiografía. Ese anclaje con lo real, con la propia experiencia, me distancia enormemente de las disquisiciones metafísicas de cierto tipo de poesía, en la que se me hace muy difícil reconocerme" (2015: 18). 
un cuerpo: "Todo estriba / en simular que nos duele la muerte. / Solo eso: hacer creer que nos aterra / morir o ver la muerte. Imprescindible / elegir una víctima que haga / las veces de un destinatario: el padre" (29).

Resulta imprescindible también, para este poeta, cumplir con los requerimientos (tanto formales como de contenido) que impone la tradición elegíaca y con las que le surgen del propio juego transgresor de su poesía. Con el tono didáctico crispado de ironía va enumerando esos requerimientos: escoger una muerte ejemplar, que justifique "una ira sin nombre"; impostar la voz, para "que se confunda con / el ciego bramido de una bestia", para así infundir piedad en el lector; adoptar, -es "recomendable", por lo menos, hacerlo- "el terceto pareado si se quiere / seguir la tradición del abandono"; y, por supuesto, leer "la elegía de Hernández a Ramón Sijé / o la que en don Francisco de Quevedo, maestro / en el arte de la infamia versificada / inmortalizara a fulano de tal" (29). La lista de deberes es extensa y explícita: "Debe ser / virtuoso el uso del encabalgamiento"; el poeta ha de "echar mano a aliteraciones de grueso calibre / para reproducir la onomatopeya del desamparo / que la elegía debe -aunque no pueda- sugerir. / El uso de la rima debe ser implacable"; se añaden, luego, ciertas consideraciones de fondo: "Importa sobre todo la verosimilitud de / tu desgarro y no el desgarro mismo: el dolor puede ser de utilidad" (30); de lo cual se desprende que: "No importa la belleza. La verdad / será requisito indispensable / a la hora de urdir una elegía / que merezca el prestigio de la muerte / o la inclusión gozosa y dolorosa / en el canon de la nueva poesía española" (30-31); hasta llegar a la constatación de aquella punzante obviedad que nos revela, sin escándalo todavía, la imposibilidad de todo arte que se empeña en negar la alta potencia de la muerte:

Deberás entender a fin de cuentas que el poema no es más que un ejercicio:

no va a hacer que se levanten los muertos ni hará que tu padre retorne del oscuro país de los dormidos porque ya no habrá país del que volver ni esperanza tampoco, ni poema (31).

Es así que, en esta verdadera escena didáctica, en la cual el sujeto se propone muy seriamente concluir un duelo, mientras que al mismo tiempo se va enseñando cómo se debería escribir una buena elegía, se logra también -mediante 
la ironía-, el extrañamiento de la tragedia de la muerte del padre; y con ello se alcanza lo inconcebible de la elegía de Rubio, esto es, el gozo o la dicha de cantar por esa muerte: la del propio padre. Pero aquello inconcebible de la elegía -recordemos las sugerencias de Eloy Sánchez Rosillo- estaba precisamente en el origen de esta expresión poética. Y el poeta Rafael Rubio vuelve al carácter celebrativo de la elegía por un camino distinto al trazado por el de Eloy: por el de la antipoesía, que funciona aquí, entre otras cosas, gracias al distanciamiento y la ironía.

Por otra parte, el poema, al ser concebido especialmente como artificio del lenguaje, permite la activación de su función ritual ${ }^{14} \mathrm{o}$, dicho de otro modo, responde a la búsqueda de una salud o sanación que solo es posible en cuanto el dolor del sujeto biográfico -el propio autor Rafael Rubio- se traspasa al sujeto textual, quien se presenta ante todo como un simulador. Solo de esta forma ese dolor se mira con distancia y de algún modo se hace soportable, tal como se desprende de las propias palabras de Rubio (ver cita textual en página 138).

14 Hasta aquí solo hemos anunciado someramente las relaciones entre poesía elegíaca y ritual. Pensamos, en este aspecto, que tanto en Sánchez Rosillo como en Rubio asistimos a la escenificación de un duelo, y por lo tanto de un ritual dedicado a la muerte, especialmente, si consideramos esta poesía como acto de habla, desde un punto de vista pragmático. En este sentido, como señala Antonio López Eire: “«hablar es hacer algo” y por tanto recitar poesía es una acción que se parece muchísimo a un ritual [...] La poesía es lenguaje que tiene mucho que ver con el rito, es lenguaje que está embebido con el ritual y que ha tomado de él sus más notorias características. Es, por decirlo bien y pronto, lenguaje ritualizado. El lenguaje ritualizado no se dice, como el que usamos todos los días, sino se canta o se recita. El lenguaje de la poesía, lenguaje ritualizado, es el que sirve para realizar «actos de habla" rituales" (López Eire 2004: 63). Otra relación sugerente, que establece López Eire a partir de Aristóteles, es aquella que permite ligar la poesía con el acto ritual de la kátharsis, que, entendida como acto de purificación, bien puede explicar las funciones prácticas de esta poesía elegíaca: "Y ya en el punto culminante de la aproximación de la poesía al ritual, Aristóteles nos enseña que la tragedia, sublime variedad de la poesía, produce un efecto de purificación o kátharsis de pasiones en quienes la contemplan en el teatro" (2004: 76); y aquello es precisamente lo que vemos y oímos en las palabras de nuestros poetas, pues al traspasar el hecho biográfico de la muerte del padre al poema, dicho acontecimiento se hace soportable, y así las pasiones del horror y la compasión se neutralizan y se disipan, para dar paso a la evocación elegíaca propiamente tal, que es al mismo tiempo sufriente y celebrativa. Sin duda, pues, la elegía está estrechamente ligada al rito, pero al rito de la muerte. Concluimos con López Eire: "la poesía es lenguaje ritualizado y el resultado de una de las actividades más genuinas del hombre, si es verdad que, como dicen los antropólogos, el hombre es un animal político-social que, para realizarse como tal, necesita del lenguaje y del ritual" (2004: 84). 
Ahora bien, dentro del marco de la escena situada en la muerte del padre, esta intención didáctica -retórica y poética- va mucho más allá, pues La Muerte, ya devenida personaje, será, dentro de la escena, aquella maestra que instruye al sujeto en el "cojonudo" arte "de escribir / sobre la piel de un cadáver" (34). Esta lección de La Muerte será, en definitiva, una lección sobre el arte de morir, o dicho de otra forma, la lección de escritura será indivisible aquí de una lección, y por lo tanto de un aprendizaje, sobre el saber y el poder morir, o incluso más allá, sobre el derecho a morir: una lección en la cual el propio sujeto - máscara del poeta Rafael Rubio- también será llamado a su propia muerte. En primer lugar, sin embargo, será necesario saber escribir una buena elegía. Solo así, se dice el sujeto a sí mismo: "Entenderás por fin que una elegía / es cosa de vida o muerte. / O bien, al menos / te será un sustituto del suicidio. / En el arte del corte de los versos / es maestra la muerte. / Deberás / aprender de ella, si pretendes / que tu elegía sea ejemplar" (33). Y ejemplar es el arte de la elegía en la voz del poeta Rubio, así como ejemplar es el personaje de La Muerte-Maestra, pero nada hay de fácil en dicho arte: "un asunto tan delicado como la muerte / requiere de tal manejo del oficio / que sería necesario la inmortalidad / para aprenderlo con éxito" (33).

Es así que La Muerte, entendida como personaje literario, es decir, como figura, personaje e incluso máscara del poeta, actúa para dar una lección al sujeto -y luego a nosotros, los lectores-, lección que aquí tiene un doble propósito o efecto: por un lado, concluir el rito de la muerte del padre, y por otro, o lo que es casi lo mismo, enseñar el propio oficio del corte de los versos, para dar un buen término a la elegía.

En este especial sentido vemos que La Muerte enseña, educa, dialoga, juega, baila, seduce y hasta fornica. Es La Muerte-Maestra, triunfante como en las estampas medievales; mujer a veces, felina acechante, como en un temprano poema de Huidobro ("El terror de la muerte"); segadora de la vida, que toca el tambor, la gaita o el pandero, como en los frescos de las Danzas de la Muerte que reescribiera el propio Óscar Hahn y también Leopoldo María Panero; o bien, aquella Pelada o Calva, o incluso más: ese "andrógino perfecto" que poetizara Lihn, más bien desconstruyendo todo posible encuentro con la "otredad radical". Pero también será aquella vieja lacha y vizcacha, que toca a la puerta de la casa del poeta, buscando el coito carnavalesco, con aquel sujeto-máscara del mismísimo Nicanor, en una escena cómica muy propia de la cultura popular y de la antipoesía parriana.

Ahí está La Maestra-Muerte, enseñando los mismos tópicos de siempre: Carpe diem, puesto que todo es Tempus fugit, y todos han de ser iguales en 
el mismo finis: ricos y pobres, poderosos y desgraciados, aunque no sepamos nunca la hora de la Mors certa. La Muerte entonces iguala, y de ahí su ímpetu democrático y social, pues de ella nadie escapa y todos vamos irremediablemente al mismo terminus, luego de lo cual los que quedan solo podrán preguntarse: Ubi sunt?, como en las Coplas de Jorge Manrique, o en el poema del mismo nombre que Sánchez Rosillo incluye en su libro Autorretratos de 1989. Sin embargo, en todos los casos será necesario, primero, ver la muerte del otro, en este caso, del padre: pues solo quien ve de cerca la muerte del padre, podrá dar buen término a su elegía.

\section{UNA DIGRESIÓN A PROPÓSITO DE LAS ELEGÍAS DE BORGES}

"Nací para dar cuenta de mi muerte". Con esas palabras, quizás tomadas de un poema, Rafael Rubio finalizaba la conversación que con él compartimos, en la tarde del 28 de enero de 2015, en un café cercano a la Biblioteca Nacional de Santiago de Chile. Pero ahora que leo su prólogo al libro Ni tallo ni renuevo, comprendo mejor cómo su propia poesía nació de la muerte del padre, del mismo Armando Rubio; y mucho más aún, cómo ese padre nació, para el hijo Rafael, a partir de su muerte. Y he aquí el escándalo de la revelación, donde lo dicho ya es casi un diálogo de muertos:

Mi padre (Armando) nació el año 1980, a los veinticinco años de edad; tres años antes de la publicación de Ciudadano, el libro que le diera oficialmente el lugar que se merece dentro de la poesía chilena contemporánea. Yo tenía cinco años, y no supe que era el hijo de un recién nacido hasta mucho tiempo después, cuando yo mismo ya era un muerto. He oído muchas veces decir que los poetas no mueren. Y a fuerza de tanto oírlo he terminado por asumirlo como una verdad. Los poetas no mueren, los que mueren son los padres, cuando los hijos mueren (2015: 15).

Sabemos, con esta última línea, que Rafael se refiere a su abuelo Alberto, quien murió -figuradamente, se entiende-, viendo a su propio hijo morir. Pero también Rafael se refiere a la muerte de su padre Armando, y en última instancia, a la suya propia. Lo obvio o extraño de esta escandalosa revelación es que apunta precisamente al nacimiento poético del padre, quien nació con su propia muerte. Y en ello hay una declaración de fe, con minúsculas, o un "principio esperanza" si se quiere, que se cristaliza en la obra literaria. Es 
así que los poetas no mueren, pero sí los padres; o bien, como lo aclara el mismo Rafael hacia el final del prólogo: "Los poetas no mueren, dijo alguien que, sin duda, debió ser un poeta demasiado envanecido por sus ansias de inmortalidad. Yo diría más bien: los poetas también mueren, pero solo por un rato" (2015: 15); el rato o el lapso, diríamos, en que la obra calla y se hunde en el silencio, hasta que otro, un lector, la revive leyéndola, pronunciándola. El padre muerto revive así en el lenguaje del hijo, al mismo tiempo que ese padre se entrega a la muerte, pero naciendo. De este modo se comprende, más tardíamente, que uno es también hijo de la muerte de su padre.

Quizás ese "poeta demasiado envanecido por sus ansias de inmortalidad", sea, ¿quién más?, ese otro padre de la literatura, un padre que precisamente no tuvo hijos: Jorge Luis Borges, poeta también, profundamente elegíaco. Me permito, pues, aquí una digresión inesperada, pero ya anunciada más arriba: Borges, tan ocupado de traducir y reescribir versos antiguos, se conduce con total naturalidad por las elegías. Sin duda, estamos en presencia de un diálogo inconcluso de la gran poesía, cuyos orígenes se pierden en la memoria del tiempo. Se podría decir, con Gilles Deleuze, que estamos ante la presencia de un bloque, de una banda de poetas elegíacos preocupados de sondear las cosas del más allá. Y la visión del último rostro surge aquí de la visión del padre muerto. Borges también escribe una elegía al padre muerto en su poema "A mi padre": "Tú quisiste morir enteramente, / la carne y la gran alma. [...] Te hemos visto morir con el tranquilo / ánimo de tu padre ante las balas. [...] Te hemos visto morir sonriente y ciego. / Nada esperabas ver del otro lado, / pero tu sombra acaso ha divisado / los arquetipos últimos que el griego / soñó y me explicabas. Nadie sabe / de qué mañana el mármol es la llave" (2011: 443).

La certeza de la Mors certa ya desvelaba a Borges desde sus primeros versos, tal como a Sánchez Rosillo, a Rubio y a tantos otros. La muerte, que era el sueño en el poema "Arte poética" de El hacedor, luego sería otro rostro o imagen del tiempo: "la muerte / ese otro nombre / del insaciado tiempo que nos roe" (407). En diversos lugares de su obra, el argentino ingresa en la ficción poética y narrativa con su propio nombre, para convertirse en el heraldo de su propia muerte. Y el nombre propio, esa sombra, lo sabe el poeta, es ya "el nombre de un muerto, la memoria anticipada de una desaparición" (Bennington y Derrida 1994: 163). El poeta, de este modo, no dudará en aparecer en su propia "Elegía", creando la figura del doble que es el muerto: el otro, finalmente, que es el mismo: "Oh destino el de Borges, / haber navegado por los diversos mares del mundo [...] Haber visto 
las cosas que ven los hombres, / la muerte, el torpe amanecer, la llanura / y las delicadas estrellas, / y no haber visto nada o casi nada / sino el rostro de una muchacha de Buenos Aires, / Un rostro que no quiere que lo recuerde. / Oh destino de Borges / tal vez no más extraño que el tuyo" (242). Y luego, volviendo a la "Elegía" de La rosa profunda, el sujeto concluirá: "Pienso en mi propia, en mi perfecta muerte / sin la urna, la lápida y la lágrima" (407). Porque ahí se dirige la última visión y la última mirada. Pero para dar ese último paso -otra metáfora de la muerte-, habrá sido necesario primero ver cómo se acaba el tiempo, haber "llorado unas lágrimas humanas". Es así que el sujeto elegíaco, situado en la proximidad de su muerte, canta y a la vez llora, por todas las cosas que fueron, casi en el mismo sentido que en la poesía elegíaca de Sánchez Rosillo. El tono nostálgico de este Borges se aproxima, en este aspecto, mucho más a la poesía elegíaca del murciano que a la del chileno; pero entre ambos, la poesía elegíaca de Borges se puede leer como un lugar de encuentro donde casi todos los poetas y versos, con o sin proponérselo, se dan cita en el mismo espacio literario.

Ese sujeto intemporal, de algún modo un espectro, ese sujeto metafísico que al mismo tiempo es un sujeto autobiográfico, es el que habla muchas veces en la poesía borgeana, pero muy especialmente aquí, en el poema "Elegía", del libro La cifra: "Sin que nadie lo sepa, ni el espejo, / ha llorado unas lágrimas humanas. / No pueden sospechar que conmemoran / todas las cosas que merecen lagrimas: / la hermosura de Helena, que no ha visto [...] Del otro lado de la puerta un hombre / hecho de soledad, de amor, de tiempo, / acaba de llorar en Buenos Aires / todas las cosas" (531).

\section{TELÓN, A MODO DE CONCLUSIONES}

La elegía es una escritura ritual (ver nota al pie número 14). En este fundamental sentido, es posible afirmar que los poetas elegíacos aquí estudiados presentan, o más bien sitúan, un espacio ritual propio, construido con sus propias palabras, mediante el cual los autores activan y actualizan un rito muchas veces inconcluso: el rito de la muerte, el cual supone la asimilación y la vivencia de las experiencias del duelo y del luto.

Aunque la elegía es un texto marcadamente destinado al otro -el muerto-, tal como se puede ver en los ejemplos de Eloy Sánchez Rosillo y Rafael Rubio, el rito contenido en ella y enunciado por medio de la palabra poética está dirigido, o más bien recae transitivamente, sobre el propio sujeto 
enunciador; y puesto que se trata de un discurso autobiográfico, este se refiere al propio poeta elegíaco: es él quien finalmente debe pasar por el rito de la muerte, toda vez que se asume el proceso de morir como un paso que no solo metafóricamente debe dar el moribundo, sino sobre todo quienes presencian dicho proceso y sobreviven a la muerte del otro, en este caso, del padre. En dicho tránsito, la poesía elegíaca, entendida como medio y expresión ritual, parece ser el hilo conductor que el poeta extiende figuradamente entre uno y otro lado del finis que es la muerte, aquel nombre inverosímil que tapona todo posible entendimiento de ese lugar y experiencia que seguimos llamando muerte. Pero, paradójicamente, entendemos con Jacques Derrida, dicho lugar es un no lugar, o más bien, un lugar de aporía (Derrida 1998).

En un sentido próximo al apuntado por Derrida en sus Aporías, podemos concluir, desde Gabriel Albiac, que el nombre de la muerte es el nombre de la nada. De ahí que solo nos quede expresar dicho acontecimiento, o si se quiere, dicha cosa, a través del uso de figuras (una de las cuales sería entender la muerte como paso), es decir, tropos del lenguaje: metáforas, mitologías, símbolos (Albiac 1996: 77). Evidentemente, el lugar privilegiado para el despliegue de estos tropos del lenguaje son las formas poéticas emparentadas estrechamente con el ritual de la muerte, como las Danzas de la Muerte medievales o, en este caso, las elegías.

Ahora bien, si la elegía es el canto y a la vez el llanto mediante el cual el sujeto-poeta invoca al otro en ausencia, vemos que en dicha invocación hay no solo un llamado o una pregunta por aquel otro que ya no está, sino también la demanda de un cuerpo, demanda en el sentido lacaniano con que Martín von Koppenfels lee otro texto poético de suma importancia para la historia de las figuraciones de la muerte en la poesía hispanoamericana: Poeta en Nueva York de Federico García Lorca (Koppenfels 2007). Si la elegía es de este modo palabra ritualizada, esto es, enunciada como rito, pues dicha palabra, así como el propio acto ritual de la muerte, sucede y se enuncia en torno a un cuerpo. La demanda del poeta elegíaco es así una petición y una pregunta sobre un cuerpo en ausencia, es decir, hay alguien, una persona, sobre la cual se está ritualizando el proceso biológico de la muerte. Y con el rito, la muerte deja de ser solo un hecho empírico y biológico, y se convierte en un hecho simbólico y poético (ritual). El cuerpo del fallecido, aquel cuerpo que está virtualmente desapareciendo, está al mismo tiempo siendo convocado, llamado al acto de su propia desaparición, aun cuando ello pueda ser tan solo una construcción metafórica en el plano del lenguaje poético. 
Este rito, lo sabemos, es finalmente para nosotros mismos, los mortales, así como el poema elegíaco está destinado no tanto al muerto (los muertos no leen, no pronuncian palabra), como a los vivos, es decir, a los lectoresespectadores que somos nosotros. Somos nosotros, en última instancia, quienes debemos aprender el rito, y en ello la poesía elegíaca parece cumplir una función didáctica, explicativa, demostrativa, si se quiere. Más aún, somos nosotros, los que sobreviven a la muerte del otro, quienes debemos vivir la agonía y dar el paso -así como figuradamente el alma da el paso para liberarse del cuerpo-, desde el llanto a la celebración, ambos componentes fundamentales de toda elegía como lo enfatizara Sánchez Rosillo, acaso porque en la poesía elegíaca se proyecta una utopía o, lo que es lo mismo, un principio esperanza: la utopía del encuentro entre los seres queridos, más allá del no lugar, más allá de la muerte, independiente de nuestras propias creencias religiosas o filosóficas.

El rito elegíaco propone así una utopía que se levanta sobre los cimientos de una metáfora esperanzadora: el muerto, al ser cantado, de algún modo revive y la muerte, por el breve tiempo que dura el trance elegíaco, parece ya no existir, aun cuando en primer término, la elegía propiamente tal sea la evidencia poética de la desaparición de una persona.

Así, siendo la muerte ya un hecho consumado, podemos volver a decir esa obviedad que muchas veces no logramos explicar del todo y que algunos discuten firmemente: la muerte forma parte de la vida, pero en el sentido de que la completa, la termina, la vuelve una unidad finita entre dos tiempos supuestamente infinitos (un antes de nacer y un después de morir), como ya hemos apuntado con anterioridad; una unidad con principio, medio y fin, si lo pensamos aristotélicamente. Y con Mijail Bajtin (2000) podemos sostener lo siguiente: con la muerte del otro, en este caso del padre, tengo toda la vida del otro frente a mí, puedo llorar y cantar aquella vida en una elegía; puedo decir, en suma: aquí está mi padre muerto, aquí mi madre muerta, y aquí estoy yo frente a ellos, cantando una elegía, tensando aquel hilo de oro que algunos, como Sánchez Rosillo, llaman poesía: aquel puente imaginario, pero extremadamente fuerte que me une a ellos, a los que ya se fueron.

En este último gesto, utópico y aporético a la vez, se cifra un devenir: a través del canto elegíaco me uno a mis deudos, soy uno con ellos, al menos en el espacio imaginario que proyecta esta poesía, incluso cuando el fin sea terminar con la muerte del padre, como lo propone implícitamente Rafael Rubio en su poema "El arte de la elegía". He ahí el gesto ético y estético de la poesía elegíaca, pues ya no se trata solo de mi dolor, como sujeto del 
luto, sino de la acción valórica según la cual el sujeto del duelo deja de vivir dicho proceso para reencontrarse, mediante la proyección utópica-elegíaca, en ese espacio, proyectado desde el más acá, donde al final estaremos todos juntos: la muerte, esa última casa.

En conclusión: hemos examinado de qué manera estas nuevas elegías, inspiradas en la muerte del padre, vuelven a actualizar la función ritual-propia de la palabra poética ancestral y/o arcaica-, puesto que éstas vienen a ser expresiones ritualizadas de las experiencias del duelo y del luto, entendidos estos como procesos de asimilación de la tragedia de la muerte del ser querido, en este caso, del padre.

La escritura elegíaca, entendida desde la poética de Eloy Sánchez Rosillo, se puede entender como una lamentación o llanto por la persona fallecida, pero al mismo tiempo, como una búsqueda de superación de esa muerte y, en última instancia, como una celebración póstuma y tardía por esa vida que se fue. Pero la visión estremecedora de la muerte del ser querido conduce, como hemos dicho, a la visión de la muerte propia, la cual será entendida, a la larga, como objeto o asunto poético de una autoelegía anticipada que, paradójicamente, se enuncia en la forma del epitafio, donde se condensa el rasgo celebrativo y elegíaco, en el caso del poeta murciano.

Por su parte, la escritura elegíaca de Rafael Rubio -muy especialmente en el poema aquí estudiado-, se puede leer, en conjunto, como una metapoesía elegíaca donde se crea una verdadera escena que es, a la vez, una conversación tanto con sus fuentes intertextuales, como con la figura ausente del padre muerto, y aún más allá, con aquella figura de La Muerte -ahora todo un personaje literario-, que viene a aparecer como la Maestra en el arte de la misma composición elegíaca.

Aunque ambos poetas se sitúan con decisión frente a esta larga tradición lírica y poética, la resolución es diferente en cuanto al estilo literario, y esto se hace notorio al contrastar sus textos, aun cuando el componente autobiográfico sea el punctum desde el cual surge la visión elegíaca en ambos poemas. Al respecto, los poemas son situados -en el sentido acuñado por Enrique Lihn respecto de su poesía y muy especialmente de su Diario de muerte (1989)- puesto que han sido enunciados a partir de una situación concreta, tanto espacial como temporalmente, es decir, un momento e incluso un lugar preciso que desborda la subjetividad de nuestros autores: la muerte del padre, esta última como circunstancia espacial y temporal, donde la conciencia humana fuertemente se estremece y desde donde surge, como única posibilidad ritual del luto y el duelo, la expresión elegíaca propiamente 
tal. En este último gesto, hemos dicho, el del cantar elegíacamente a esa vida que se fue, se proyecta una utopía, un sueño o una esperanza: mediante la invocación del otro en ausencia, es posible que el canto se transforme en un nuevo encuentro con aquel ser querido que se fue, más allá de aquella última mirada que nos brinda la muerte.

Para terminar... ¿Cómo dar notable fin a una elegía? Dirá Sánchez Rosillo:

$$
\text { Entonces no lo supe. }
$$

Pero hoy sé que esas horas en que tomé conciencia

Del tiempo y de la muerte arrasaron mi infancia:

Dejé allí de ser niño.

La casa fue llenándose

Poco a poco de gente. Familiares y amigos

Daban con su presencia lugar a repetidas

Escenas de dolor. La noche no avanzaba.

Parecía que nunca iba a llegar la aurora (2014: 239).

\section{Y Rafael Rubio:}

Así de grave

y cojonudo el arte de escribir sobre la piel de un cadáver.

ve la muerte de su padre, podrá dar

Sólo quien

notable fin a una elegía

(como éste)

$¡$ ¡Un remate que haga remorderse de envidia

-en su tumba-

a Quevedo, a Fray Luis, a Garcilaso! (2010:34).

\section{BIBLIOGRAFÍA}

Albiac, Gabriel. La muerte. Metáforas, mitologías, símbolos. Barcelona: Ediciones Paidós Ibérica, S. A., 1996.

Bajtin, Mijail. Yo también soy (Fragmentos sobre el otro). México D. F.: Aguilar, Altea, Taurus, Alfaguara, S. A., 2000.

Bennington, Geoffrey y Jacques Derrida. Jacques Derrida. Madrid: Ediciones Cátedra S. A., 1994.

Blanchot, Maurice. De Kafka a Kafka. México D. F.: Fondo de Cultura Económica, 2006. 
El espacio literario. Barcelona: Paidós, 2000.

Borges, Jorge Luis. Obra poética. Buenos Aires: Editorial Sudamericana, S. A., 2011.

Derrida, Jacques. Morir-esperarse (en) "los límites de la verdad". Barcelona: Ediciones Paidós Ibérica, S. A., 1998.

Eire, Ana. Conversaciones con poetas españoles contemporáneos. España: Editorial Renacimiento, 2005.

Escavy Zamora, Ricardo (Ed.). La poesía de Eloy Sánchez Rosillo: El ruido del tiempo. Murcia: Universidad de Murcia, servicio de Publicaciones, 2007.

Infante, Magdalena. "Luz rabiosa: para un padre y el otro". Taller de letras, n 42, pp. 215238. Santiago: Ediciones Universidad Católica de Chile, 2008.

Jankélèvitch, Vladimir. La muerte. Valencia: Pre-Textos, 2009.

Koppenfels, Martín von. Introducción a la muerte. La poesía neoyorquina de Lorca y el duelo de la lírica moderna. Kassel: Ediciones Reichenberger, 2007.

López Eire, Antonio. "Lenguaje, ritual y poesía". Logo: Revista de Retórica y Teoría de la Comunicación. Año III, $\mathrm{n}^{\circ}$ 7, diciembre, pp. 63-86. Salamanca: Asociación Española de Estudios sobre Lengua, Pensamiento y Cultura Clásica, 2004.

Marchese, Angelo y Joaquín Forradellas. Diccionario de retórica, crítica y terminología literaria. Barcelona: Editorial Ariel, S. A., 2000.

Pérez Navarro, Julián (Director de la edición). Historia del Colegio Oficial de Aparejadores y Arquitectos Técnicos de la Región de Murcia. Murcia: Colegio Oficial de Aparejadores y Arquitectos Técnicos de la Región de Murcia (COAATMU), 2009.

Rubio, Rafael. Luz rabiosa. Santiago: Camino del Ciego Ediciones, 2010.

Rubio R. Alberto, Armando Rubio H. y Rafael Rubio B. Ni tallo ni renuevo. Santiago de Chile: Editorial Universitaria S. A., 2015.

Sánchez Rosillo, Eloy. Las cosas como fueron. Barcelona: Tusquets Editores, S. A., 2004. Hilo de oro (Antología poética, 1974-2011). Madrid: Ediciones Cátedra (Grupo Anaya, S. A.), 2014.

Sepúlveda Eriz, Magda. "El territorio y el testigo en la poesía chilena de Transición”. Estudios Filológicos $\mathrm{n}^{\circ} 45$, pp. 79-92. Valdivia: Instituto de Lingüística y Literatura, Facultad de Filosofía y Humanidades, Universidad Austral de Chile, 2010.

Warnken, Cristián. “Transcripción de entrevista a Rafael Rubio". Una belleza nueva (programa de televisión), abril, www.unabellezanueva.org. Santiago de Chile, 2008. 